\title{
Introduction \\ Health and Welfare: Diversity and \\ Convergence in Policy and Practice
}

\author{
Laurinda Abreu
}

s several authors have pointed out, the history of the health in society is
deeply linked to the epidemic experiences of Western Europe but it also
goes beyond it. The way the concepts of welfare, health and public health were shaped and evolved ever since the late middle ages were dependent on the specificity of the social, symbolic and cultural representations, the economic resources, the social organization and the characteristics of the political powers, among many other factors. They explain the complexity of the processes, the composite, and sometimes even contradictory, solutions implemented in order to face similar problems in related contexts. However, in spite of the diversity of answers, it is possible to find common institutional patterns all over Europe since the beginning of the process, considered here as the moment of the first systematic and continuous institutionalized intervention of the authorities in terms of poor relief, health care and welfare policies. And this is mostly due to the common religious and cultural background and the political agenda, in other words the emergency of the early modern state. What remains quite amazing is the promptness by which the information circulated since late medieval times, in part accompanying the trade dynamics, but also because the Papacy was an important diffusion center of social policies, and, above all, because the interest of the political authorities to know the best practices, namely on the epidemics control and hospitals administration, mobilized in the search of common answers for common problems.

In the long-term perspective, and in a very broad sense, it is confirmed that each moment of rupture in terms of the social support systems was also an occasion for a general modernisation of health and social solidarity structures. In the present moment the social sciences researchers may have a word to say.

This Hygeia volume results from the conference Health and Welfare: diversity and convergence in policy and practice, organized by PhoenixTN - European Thematic Network on Health and Social Welfare Policy, held in Athens in February 
2009. Created and financed under the auspices of the European Commission in 2001, in the framework of the Socrates-Erasmus programs, PhoenixTN congregated more than eighty partners, mainly universities, from all around Europe. During several years, the project worked as a very active forum for the discussion of public health and welfare policies, in a very extensive sense. Taking the project' members background disciplinary diversity and multiplicity of methodological and theoretical approaches as an added value, PhoenixTN capitalized it through conferences, seminars and workshops but also in books, journals, educational programs and academic inter-exchanges.

The Athens conference was the final conference of the PhoenixTN and this journal issue is its final publication. As in the previous books, the papers presented reflect the above mentioned diversity, either in terms of methodology or analysis.

\section{Institutions, Political Powers and Health and Welfare Policies}

The wide geographic examples and chronologic approaches offered by the papers published here have some positive aspects: for instance, it permits to analyze the historical developments of the processes and even their similarities, which is a crucial factor for the comparative approaches. It also calls our attention for the necessity to put the research in a perspective. Some revolutions may only express more attentive and more precise administrative procedures. As Fritz Dross writes in his paper, "Patterns of Hospitality: Aspects of Institutionalization in 15th \& 16th Centuries Nuremberg Healthcare", referring_to late-medieval and early modern hospitals, sometimes it is not the way to do things that radically changed but how it was registered.

Focusing on the developments of the institutional welfare provided by the Nuremberg hospitals, Fritz Dross examines the organization of the support for the foreign lepers in the framework of a city where, since very early, the hospitals were divided according to the different types of needs and patients, based on a very flexible structure, established on subsidiary principles, adaptable to conjunctural necessities. The use of the hospital care as an attempt of social control, of the lepers as well as of the other sick, not necessarily poor, and the prompt discharge of the recovered inmates, is presented by the author as signals of modernity in the hospitals' history.

Among the poor relief and health care institutions, the medical hospitals ${ }^{1}$ were, probably, in the European context, the establishments with most common characteristics, no matter the geographic place concerned. In "Healing the body and sav-

1 Taking into account that we are dealing with a polysemic word but excluding from this broad designation the French General Hospitals. 
ing the soul in the Portuguese hospitals of the Early Modern Age" Maria Marta Lobo de Araújo and Alexandra Esteves describe the Portuguese example of the diversity of the early modern hospitals, either in terms of capacity, functions and patients. Resulting from the amalgamation process started in the last years of the $15^{\text {th }}$ century, organized according to the Regiment of the Lisbon Hospital de Todos os Santos (1504), and systematically transferred to the lay confraternities of Misericórdia after the Council of Trent, these hospitals reflect the dynamics of the communities where they were placed. In urban communities, for example, the patients were mainly migrant workers while in the workers' rural areas the hospital clientele was essentially female. If the lack of medical staff was a general feature of medieval/early modern hospitals, a great number of them were provided at least with one physician with academic training, apart from other healing professionals. That this was an ordinary situation also in Spain is confirmed by María José Pérez Álvarez' paper, "Disease and health care in the North-West of Spain in the early modern period. The Bierzo region". As expected, the Queen's Hospital, in Ponferrada, studied by Maria José, didn't accept incurable people or patients with contagious diseases because it was assumed as a space of cure: as frequently contemporaries hospitals' records refer "good food and a bed is the best therapeutic that the main part of patients need".

In the broad sense of cure when applied to these hospitals, apart from the medical therapy, the spiritual care provided could play a pivotal role. But most certainly the early modern authorities had other preoccupations beyond the patients' souls. The way some of them allowed the workers to use the early modern hospitals is a good indicator of the multiple functions that those spaces could assume. Among manifold objectives was the care of abandoned children, institutionalized in Europe at the early $16^{\text {th }}$ century, financed, in some cases, with local taxes.

The foundlings' question can't be isolated from the legislative persecution of beggars and vagrants, also intensified since the beginning of the $16^{\text {th }}$ century, as Alfredo Martín García notes in "Childhood and poverty in Leon in the modern period: Institutional responses". The European authorities, religious or not, have considerably invested in charitable institutions for children - three in early modern Leon -. The financial problems that they found, in Spain as in every catholic country, impelled them for a paradoxical situation: although created to prevent the children from begging, when we analyze their budgets we realize that part of their incomes resulted from alms collected by the students. In the main part of the cases, the educational and vocational training objectives of these institutions didn't resist to their precarious economic situation. The same occurred with the children.

The concern of the early modern authorities with the population health and welfare, in a deeper sense than that reported by George Rosen in his seminal book, History of Public Health, is also revealed in Laureano Rubio Pérez's paper, "Barbers, doctors and healers: Community welfare and the health system in the North-West 
of Spain - the province of Leon - during the seventeenth and eighteenth centuries". In a political scenario characterized by the absence of the crown and strengthening the power of the local councils and corporations, it was these local institutions that organized and distributed poor relief and the health care resources, guarantying direct positive effects on the populations' health. On the other side of the frontier, since 1568 that the Portuguese Crown was imposing to several municipalities the financing of the academic training of physicians, surgeons and apothecaries destined to attend the poor from the inner and rural communities. The political actors differed but the assumptions were basically the same in different countries. The direct intervention of the local elites was the key for the implementation of new poor relief and heath care structures. This was the case even in Portugal, where the political power was more centralized than in other countries. The16th century Portuguese monarchs were able to convince the dominant groups to put into practice their ideals and values negotiating with them and granting them several social and political benefits.

However, as Juan Gracia Cárcamo analyses in "Women, families and social welfare in Spain from the $18^{\text {th }}$ century to the present", the long-lasting presence of the political authorities in the poor relief and health care arena can't lessen, in analytical terms, the presence of other agents, formal or not ${ }^{2}$. Recuperating the idea of the families, and the role of the women inside the families, as the main social protection resource from poverty, the author contests some recent revisionist interpretations, defending that the $20^{\text {th }}$ century Spanish care model only can be understood taking into account the long-term historical perspective, and doing it, is not possible to deny the importance of families and women as suppliers of well-being.

The question on how the political powers intervene on the public health field and the capacity to impose, or not, their objectives is also the subject of the next four papers. In "State's medical experts in local practice. Provincial doctors view of themselves as public health promoters: an example from the Swedish countryside, 1880-1920", Anna Prestjan addresses the emergency of the Swedish welfare state, at the end of the $19^{\text {th }}$ century, analyzing the case of the sparsely populated district of Sveg, in Northern Sweden, through the worked developed by the provincial doctors - medical experts nominated by the Swedish state for the countryside communities. And her conclusions are quiet clear and easily understandable. The provincial doctors assumed themselves as central government informers and community reformers, rejecting any sort of integration into the places where they were working, were unable to cross over the local logics and to access the very competitive medical marketplace where other health providers dominated and different healing services were offered. This is a situation not very different from the one presented by Alex-

2 For this question see, Dinges, Martin, "Health between Self-Help, Formal and Informal Institutions", Abreu, Laurinda (ed.), European Health and Social Welfare Policies, Santiago de Compostela, 2004, pp. 21-50. 
andra Esteves and Maria Marta Lobo de Araújo in "Cholera in the Portuguese region of Alto Minho in the second half of the nineteenth century: Epidemic outbreaks, treatment and behaviours". In the context of the first International Sanitary Conferences, the hygienist ideology and the medical police principles, the Portuguese state only hardly succeed to implement a more efficient sanitary control and preventive measures against cholera. The authoritarian way the central government tried to impose its policies faced serious resistance from the poor people, refusing to accept orientations that made their daily life even more difficult than it already was.

Using a completely different approach, the Bourbon Crown was able, approximately at the same time studied by Anna Prestjan, to develop a massive public health vaccination campaign against smallpox in Sicily, "one of the earliest examples of state-sponsored non-compulsory immunisation programmes in history", to quote John Chircop, in 'Giusta la benefica intenzione del Re': the Bourbon cowpox vaccination campaign in Sicily". For the success of such a project, the crown established a well organized scheme involving the most important structures of the central and local governments, but also the communities' actors, as the Church and the health professionals. The result is described by Chircop as a paradox: combining a "deeply entrenched conservatism with a drive for administrative modernisation, particularly in the fiscal system and in public health", the Bourbon government succeeded to impose new scientific ideas in what concerns public health, capitalizing it according to the most elementary bio-politic principles of health prevention and social surveillance. One of its instruments was the administrative bureaucracy, more and more efficient to report and to produce empirical data.

The importance of the administrative structures as provider and manager of information is also a central point in Elzbieta Kaczynska' and Panagiotis Eliopoulos papers. In "A Century of Social and Economic Change - Its Impact on Health and Welfare (Poland between 1815 and 1914)", Kaczynska, discussing the development of health and welfare offered in a very particular political situation, accents the big investment done by the state in terms of hygiene and health care explaining the increase of the number of patients and the criticism against the system, not by the inefficiency of the professionals involved but by the efficiency of the administrative structures, whose development gave more visibility to the data, making possible the entrance of more people into the medical system. For Panagiotis Eliopoulos, studying the Greek maritime city of Patras, in "Matters of Life and Death" in a Mediterranean Port City. Infrastructure, Housing and Infectious Disease in Patras, 19011940 ", the scarcity of venereal disease and TB among the death records of adults didn't reflect the absence of such illnesses in the city epidemiologic agenda (for example they were very present in the death records of the foundlings), but the fear of social stigmatization and also due to the political constrains in assuming the real dimension of diseases considered responsible for the creation of generations of degenerate murderers. In Poland, the administrate structures were used to give great 
visibility to old problems and it contributed to social panic. In Greece the public administration hid the real data in order to protect the reputation of the population and of the city.

\section{The Multiple Forms of Vulnerability}

The second group of papers aggregates different situations of vulnerability ${ }^{3}$. The first two are referring to vulnerability among young people, in Andrea Fabian's paper, "Juvenile delinquency in Romania: the indirect result of the transition process", and among the minorities in the context of the labor market, in Oscar Fernández' s paper, "Wellbeing and Work. Social Inclusion of Vulnerable Groups in Northern Spain". Andrea Fabian discusses the anti-social behavior and delinquency of young people. The big social expectations created after the communist regime in Romania, together with the economic changes that fomented the rural exodus, worsening the living conditions in the cities, and the governments' incapacity to respond to the aspirations of the population, contributed to the increase of the criminality. Rootless, the rural young people became urban delinquents. Direct result from the desocialization processes, so common nowadays in big urban centers, only a more assertive role of the family and of the school can, according to the national public opinion, prevent this type of juvenile criminality. It is precisely the constrains resulting from the educational and social limitations that constitute the most important handicaps presented by Oscar Fernández when he analyzes the difficulties experienced by vulnerable groups in the access to the labour market, in the urban district of Ponferrada, Province of Leon, in Spain. Women at risk (the most represented), disabled, immigrants, addicted (or ex-addicted) people, homeless or ethnic minorities, as the Romany community, are the groups at risk of social exclusion, being urgent to create conditions to help them to find an employment, the most efficient way to avoid anti-social behaviours, such as mentioned by Andrea Fabian. According to the author, the solution can reside in a sort of tailormade inclusion routes, with financial and social support, organized according to a specific agenda under a flexible methodology, also able to involve the enterprises.

The other papers in this second set deal with the modern demographic behaviours and the enormous challenges that they are creating to the Social Protections Systems and National Health Services. Among the problems studied, the contemporary societies ageing process, and the associated problems, is the most present.

3 For the different concepts of vulnerability and their historical construction see, from Patrice Bourdelais and John Chircop, "Situating and defining vulnerability in historical perspective", in Vulnerability, Social Inequality and Health, Patrice Bourdelais and John Chircop (eds.), Edições Colibri, CIDEHUS/UE, PhoenixTN, Lisboa, 2010, pp. 7-14. 
Different perspectives and approaches are discussed, covering a vast range of problems and sources.

Crossing national and municipal demographic data with welfare indicators, from 1960 to 2007, Teresa Ferreira Rodrigues explores, in "Regional Dynamics and Social Diversity - Portugal in the 21st Century", the regional differences and asymmetries reflecting on how the broad demographic and socioeconomic changes occurred in the Portuguese society of the last decades affected such parameters. Concluding that, in spite of the convergence on national demographic behaviours, the homogenization on well-being standards is far from being reached. Rural and interior municipalities are the losers of the development process. Teresa Rodrigues is not far from one of the central ideas of Maria João Guardado Moreira's paper, "Environmental changes and social vulnerability in an ageing society Portugal in the transition from the 20th to the 21st centuries". The Portuguese National Health Service is unable to successfully deal with the new economic and social dynamics. When it concerns the extensive demographic ageing course, the new morbidity and mortality patterns and the growing demand in terms of patients, the institutional health and social structures still have a long way to go in order to offer good conditions to the elderly people.

The general reconfiguration of society and the new models and families' organization, a key point in the ageing societies, as shown in the Portuguese example, is also present in the study of Jolana Rambousková, Eva Kř́žzová, Pavel Dlouhý, Jana Potočková and Michal Anděl, "Nutritional Status in Elderly People Living in Retirement Homes in the Czech Republic". Evaluating the nutritional status (a crucial determinant of health) of elderly admitted in institutions and comparing it with the ones living alone or with their families, the authors conclude that the institutionalized elderly show higher levels of poor nutritional statutes, accounting for long-term hospitalizations and considerable post-hospitalization care. This means that the institutionalization of the elderly, a recent practice implemented in the Czech Republic, not only increased the financial costs of the health system but also had repercussions in the quality of life of the people involved.

Ageing people, institutionalized care, economic resources and health problems is also the topic of the two last papers of this group: "Health Promotion Programs, for the Elderly in Greece, the "Health Pro Elderly" Project", by Panayota Sourtzi, Vasiliki Roka, Venetia Velonaki_and Athena Kalokerinou, and, by Antigone Lyberaki and Platon Tinios, "The social and economic effects of deterioration in health: 'Naked-eye' evidence from a European panel survey". In the first case, the investigation presents and discusses the Greek experiences of very popular programs in Europe nowadays - the Health Promotion Programs for the Elderly. Aiming to identify the criteria responsible for the success of those programs and practices they conclude that the main part of those projects is developed in Open Care Centres for Elderly, the majority placed in urban areas, which configures an evident situa- 
tion of inequality in the access to health resources. In spite of this, the "Health Pro Elderly" projects have produced very positive effects in terms of health promotion for this vulnerable group in Greece as well as in other parts of Europe, the reason why the authors suggest a more intense European cooperation regarding policies and strategies in order to combat the negative consequences resulting from the lack of resources felt by those who works on the field.

The paper of Antigone Lyberaki and Platon Tinios also deals with the role of social solidarity and cohesion for disadvantaged elderly people. Being recognized as one of the most important features of the European Welfare model, the authors wanted to evaluate its level of effectiveness through the amount and quality of social reserves mobilized to help individuals between 50 and 80 years old, with approximate socioeconomic patterns, that had experienced a situation of a suddenly and serious health deterioration. The study, carried out in different European contexts between 2004 and 2006/7, according to the organization of the social protection systems proposed by Esping-Andersen, uncovered different responses according to the social protection system analyzed but presents similar conclusions. On the one hand, the importance of an early response from the social systems to a social and family emergency; on the other hand, that is not the amount of money allocated to the National Health Service that determined their efficiency but how it is used.

To conclude this brief introduction, a separate reference to the text of Clara Oberle, a comprehensive studied, based on a vast range of primary documental sources, entitled, "From Warfare to Welfare, Postwar Homelessness, Dislocation, and the Birth of the Welfare State in Europe: The Case of Berlin 1945-1949". If the necessity of reinvention of the European social welfare model in order to reconstruct the social cohesion is a topic in the main part of the papers presented in this volume, it is Clara Oberle that affirms it in the most assertive way. Analyzing the particular case of Berlin in a moment of housing and health crisis, she highlights the remarkable consensus created in the postwar period regarding the importance of "public planning, spending, and state involvement in the health and welfare sector". Making welfare and public health important questions of governability, it was that interventionist consensus, in Germany like in many other European countries, that made it possible to consolidate the European social model. Like other historians, Clara Oberle suggests that the present crisis can be the moment to re-invent the health and welfare policy of Europe, based on shared values and convergent constraints. The scholars of PhoenixTN have contributed to this discussion. I'd like to thank all of them to have been so participative in tackling the multiple challenges that arose in this project context. Allow me to address a special compliment to the PhoenixTN scientific council for having invested part of their time, knowledge and energy to make it work. 